\title{
Higher body mass index, less exercise, but healthier eating in married adults: Nine representative surveys across Europe ${ }^{\text {ir }}$
}

\author{
Jutta Mata a, b, *, Ronald Frank ${ }^{\text {c }}$, Ralph Hertwig ${ }^{\text {a }}$ \\ a Max Planck Institute for Human Development, Lentzeallee 94, 14195 Berlin, Germany \\ ${ }^{\mathrm{b}}$ Department of Psychology, University of Basel, Missionsstrasse 62a, 4055 Basel, Switzerland \\ c Gesellschaft für Konsumforschung e.V, Nordwestring 101, 90319 Nuremberg, Germany
}

\section{A R T I C L E I N F O}

\section{Article history:}

Available online 6 June 2015

\section{Keywords:}

Body weight

Marital status

Exercise

Eating

Representative survey

Europe

\begin{abstract}
A B S T R A C T
Numerous studies show that married individuals enjoy better health than those who were never married. This representative survey examines whether they also have a healthier body mass index (BMI) and weight-related behaviors, and tests four independent explanations. Face-to-face interviews were conducted with representative samples $(N=4555)$ from nine European countries (Austria, France, Germany, Italy, the Netherlands, Poland, Russia, Spain, UK). On average, never married respondents had a lower BMI than married respondents $(p=.048)$. Married individuals reported stronger preferences for organic/ fair trade food and regional/unprocessed food, and paying less attention to dietary convenience or dietary fat and body weight. Importantly, married men also exercised less (all $p s<.05$ ). Despite these behavioral differences, only attention to dietary fat and body weight $(p=.001)$ predicted BMI differently for married versus never married men. There were few country differences in the relationship between marital status and BMI. All analyses were controlled for age and socio-economic status. In conclusion, despite more favorable eating-related cognitions and behaviors, married respondents had a higher BMI than never married respondents, but differences were small. The link between marital status and BMI cannot be fully described by one single explanation. Obesity interventions may benefit from considering specific weight-related behaviors in married versus never married individuals.
\end{abstract}

(c) 2015 Elsevier Ltd. All rights reserved.

\section{Introduction}

Are married people healthier? The short answer is yes. Numerous studies have demonstrated that married individuals enjoy better health and longevity than those without a partner (Umberson and Karas Montez, 2010; Waite and Gallagher, 2000; see Wilson and Oswald, 2005; for a review; but more recent studies have not found differences in health dynamics between married and cohabiting couples, e.g. Kohn and Averett, 2014a, 2014b; Musick and Bumpass, 2012). An important indicator of general health is the body mass index (BMI). Excess body weight and

\footnotetext{
We are grateful to Susannah Goss, Mattea Dallacker, and Andrea Meyer for their help with the manuscript. We also thank the library of the Max Planck Institute for Human Development, particularly Nicole Engelhardt, for help with the literature search.

* Corresponding author. University of Basel, Department of Psychology, Division of Health Psychology, Missionsstrasse 62a, 4055 Basel, Switzerland.

E-mail addresses: jmata@mpib-berlin.mpg.de, jutta.mata@unibas.ch (J. Mata), ronald.frank@gfk-verein.org (R. Frank), hertwig@mpib-berlin.mpg.de (R. Hertwig).

obesity are risk factors for numerous diseases, including ischemic heart disease, diabetes, and certain forms of cancer (World Health Organization [WHO], 2013). Are people who are married also better off than never marrieds on this indicator of health?

\subsection{Conceptualizing the link between BMI and marital status}

There are several competing, but not necessarily mutually exclusive, explanations linking BMI and marital status. The marriage-market explanation suggests that individuals who are married, and thus no longer concerned with attracting a mate, gain weight. Following the same logic, divorcees strive to lose weight when they re-enter the marriage market (e.g., Averett et al., 2008; Lundborg et al., 2007). In contrast, the marriage-selection explanation posits that people with a lower BMI-an indicator of attractiveness (e.g., Tovée et al., 1998) and health (WHO, 2013)-are more likely to be selected as marriage partners (Mukhopadhyay, 2008). According to this approach, it is not marriage per se that affects health indicators such as BMI (see also Fu and Goldman, 1996); rather, people with better health or lower BMI are preferentially 
selected into marriage. Consistent with this explanation, obese women in the U.S. are less likely to marry than are women of normal weight (Averett and Korenman, 1996), notwithstanding an overall marriage rate of over 90\% (Kreider and Ellis, 2011).

In sum, the two explanations make conflicting predictions about the link between BMI and marital status. The marriage-market explanation predicts that married individuals have a higher BMI than never marrieds, supposedly as a result of being released from the pressures of the marriage market. The marriage-selection explanation, in contrast, predicts that married individuals have a BMI comparable or lower to that of never marrieds, supposedly because a relatively low BMI is associated with higher attractiveness and better chances of being selected into marriage. The marriage-market explanation leaves open the behavioral changes that result in BMI increase when people get married. Two other explanations, however, have addressed those potential changes.

\subsection{Behaviors that link BMI and marital status}

The negative-protection explanation assumes that marriage comes with spousal obligations such as regular family meals (Sobal and Rauschenbach, 2003). Dining together, relative to dining solo, can have various consequences: For one, people often consume more calories in company than they do alone (see Herman et al., 2003; for a review). Further, the poor but seductive eating habits of one spouse may migrate to the other. Indeed, Worsley (1988) showed that husbands detrimentally influence the diet of their wives by increasing the consumption of fat and meat while reducing that of fruit and vegetables. Also, married individuals, particularly women, have been found to exercise less than those who are never married (Rapp and Schneider, 2013). Consistent with these findings, the negative-protection explanation predicts that, in a marriage, weight-controlling behaviors (e.g., regular exercising) will be "crowded out" and less healthy eating habits (e.g., consumption of convenience food) will spread; consequently, the BMI of married individuals can be expected to be higher than that of never marrieds.

In contrast, the marriage-protection explanation proposes that marriage has advantageous behavioral consequences for health and weight. For one, spouses can monitor each other's health behavior, keeping the other from engaging in risky behaviors such as the frequent consumption of high-calorie food or supporting them in being physically active (Khan et al., 2013). Relatedly, married couples also tend to have more financial resources (Averett et al., 2008) and are thus better able afford a healthier lifestyle (e.g., buying fresh produce or a gym membership).

\subsection{Mixed empirical findings concerning BMI and marital status}

Echoing the conflicting predictions of the explanations reviewed above, empirical findings on the relation between BMI and marital status are mixed: Some cross-sectional studies have found that married individuals have a lower BMI (e.g., Noppa and Bengtsson, 1980; in a population sample of Swedish women; Sund et al., 2010; in a sample of Norwegian men and women); other studies have found no differences in the BMI of married and never married individuals (e.g., Kittel et al., 1978; in an industrial population of Belgian men; Umberson et al., 2009; in a U.S. national sample); and still other studies have observed married individuals to have a higher BMI (e.g., in a large Australian random sample, Ball et al., 2002; in a national US sample, Hahn, 1993; in representative German samples, Heineck, 2006, Klein, 2011; and in representative U.S. samples in which only married men-not women-had a higher BMI, Sobal et al., 1992; Wilson, 2012). Mixed results have also been obtained in longitudinal studies: Although studies examining weight changes across marital transitions (e.g., from being single to getting married) often show that either both partners (Averett et al., 2013; Meltzer et al., 2013) or women, in particular, gain weight, other studies have found no such regularity (Dinour et al., 2012 for a review).

Importantly, very few studies have compared the relation between BMI and marital status across countries. These studies report mixed findings (e.g., non-married women in Denmark being more likely obese than married women; no such difference for women from Finland in cross-sectional samples, Sarlio-Lähteenkorva et al., 2005). One potential explanation for such mixed findings might be country differences. For example, the nine countries surveyed in this study differ substantially regarding their marriage and divorce rate (Eurostat, 2015; data for Russia are provisional data for 2011 from United Nations Statistics Divison, 2014), as well as in their risk of getting a divorce (ranging from $26 \%$ in Italy to $63 \%$ in Spain; calculated following Lundborg et al., 2007; by dividing the number of divorces in 2012 by the number of marriages in 2012, with the exception of the UK, France, and Italy, where numbers are from 2011). Because of these differences between countries, differences in the relation between BMI and marital status across countries could be expected. For example, in countries with a high divorce risk such as Spain or France, the marriage-market explanation would predict that married individuals should have a lower BMI than in countries with a comparatively lower divorce risk, such as Italy or Poland (see also Lundborg et al., 2007).

\subsection{Research goals}

In this article, we compare the link between marital status and BMI across representative cross-sectional samples obtained from nine European countries. Additionally, we examine potential behavioral causes of the link between marital status and BMI-specifically, eating and exercise cognitions and behaviors.

To our knowledge, this is the first investigation of marital status, BMI, and weight-related behaviors to draw on comparative representative samples from multiple European countries. This investigation is timely for several reasons: The mixed results reviewed above often stem from studies conducted in different countries. Country differences may be one reason for the mixed findings. To address this possibility, representative samples from nine different countries are compared. Relatedly, one of the major limitations of previous research is that the assessment of key variables differs widely between studies (e.g., some differentiate between cohabiting and being married, others do not; Dinour et al., 2012). This study uses the same measures across all samples. Further, we are not aware of investigations of the relationship between BMI and marital status in some of the eastern European countries included (e.g., Russia or Poland); thus, we enter uncharted territory. Finally, using the same samples, we investigate both the explanations advanced in the marriage-market and the marriage-selection explanations, and explore the behavioral changes suggested in the negative-protection and marriage-protection explanations.

\section{Methods and procedures}

\subsection{Participants and procedure}

Participants were 10226 individuals from nine European countries: 541 from Austria, 999 from France, 2062 from Germany, 1010 from Italy, 508 from the Netherlands, 1013 from Poland, 2016 from Russia, 1020 from Spain, and 1057 from the UK. The data were collected in fall 2011 by the non-profit branch of the Gesellschaft für Konsumforschung, an international market research institute from Nuremberg, Germany, as part of the Lifeworlds Survey. 
Sampling was done using the quota method. In quota sampling a population is stratified in mutually exclusive sub-groups; interviewers are then told to find a certain number of individuals to match a sub-group. To reduce interviewer bias in the current study, each interviewer was only allowed to find up to four survey participants. Participants were representative of the populations of these nine European countries with respect to gender, age (among those 16-20 years and older), employment status, size of household, and region of residence according to population census data in 2011; sample size per country was chosen to maximize representativeness for these characteristics considering population size. In the analyses, each country was weighted according to its population size to achieve representativeness for this European region. Only those participants were included in the present analyses who were either (a) never married and lived alone or (b) married and had a household size of at least two (e.g., if they reported living without children, the household size had to be exactly two; if they reported having one child, the household size had to be exactly three). Participants who reported being separated, divorced, or widowed were excluded, because in a cross-sectional sample it is impossible to disentangle the effects of a previous marriage versus being single/living alone. In the analyses reported in this manuscript, participants who were in a relationship but not married were excluded: Cohabitation appears to be associated with different health consequences than marriage (e.g., Horwitz and White, 1998); furthermore cohabitation has been reported to be less stable than marriage (Brown, 2000), which may affect BMI, health behaviors, or both. These conditions resulted in a subset of 4555 participants, of whom 775 were never married (448 men, 327 women) and 3780 were married (1891 men, 1889 women). Importantly, some studies have not found differences in health between individuals who are married and individuals who cohabit (Kohn and Averett, 2014a, 2014b; Musick and Bumpass, 2012). Therefore, we have conducted robustness checks by running an additional set of analyses combining co-habiting and married individuals into one subgroup (resulting in 4617 individuals in the married/co-habiting group, of which 2323 were male and 2294 were female; see Supplementary Materials, Table S3 for participant characteristics, and Tables S5-S8 for results of analyses with this group).

The study was conducted in agreement with the ethical standards of Arbeitskreis deutscher Markt- und Sozialforschungsinstitute e.V., those ethical standards were accepted by the Institutional Review Board of the Max Planck Institute for Human Development, Berlin, Germany. All participants gave informed consent and acknowledged that they could stop the interview at any time without further consequences. Participants were interviewed in their homes using a computer-assisted personal interview, except for participants in Russia who for security reasons were interviewed using paper-and-pencil questionnaires.

\subsection{Interview questions}

Interview questions were asked in the respective language of each country. The questions were first formulated in German, then translated by professional translators into the languages of the other participating countries and finally translated back into German to assure their accuracy and equivalence. Questions and answer categories were field tested and adjusted as needed.

Eating-related cognitions and behaviors were assessed with 44 items, responses to which were given on a 4-point Likert scale from 1 (does not apply at all) to 4 (applies fully). All items were subjected to exploratory factor analysis with varimax rotation. Inspection of the scree plot suggested a six-factor solution with eigenvalues above 1.4 ; three items with a factor loading lower than 0.3 were excluded. Due to the very low reliability of two factors (containing a total of 12 items), the total number of factors was reduced to four. These four factors can be described as follows: preference for organic and fair trade food, with five items (e.g., "I prefer to buy organic food and drinks"; Cronbach's $\alpha=.83$ ); dietary convenience, with 13 items (e.g., "I often use convenience food; canned/dried soup or frozen pizza"; Cronbach's $\alpha=.72)$; awareness of dietary fat and body weight, with six items (e.g., "I favor food items and products with reduced fat levels"; Cronbach's $\alpha=.63$ ), and preference for regional/ unprocessed food, with five items (e.g., "I often use food items produced or grown in the region where I live"; Cronbach's $\alpha=.67$ ). The 44 items that make up these four factors are described in the Supplementary Materials (Table S4).

Exercise behavior was assessed by one item, "How often do you exercise to keep fit?" Responses were given on a 5-point scale from 1 (never) to 5 (every day or most days).

\subsection{Statistical analyses}

To achieve representativeness of the data for the populations of the nine European countries, probability weights based on gender, age, employment status, size of household, and region of residence were applied in the descriptive analyses and all inferential statistics. Data were analyzed using the Complex Samples Software, SPSS Version 21, and Stata 13. Further, age and indicators of socioeconomic status (i.e., income, level of education, and profession of head of household) were included as covariates in all inferential analyses; country was included as covariate in all analyses across the nine countries surveyed. Missing data in the data presented here were deleted listwise; the proportion of missing data for each demographic variable is reported in Table 1. Importantly, all analyses were also conducted on a data set that used multiple imputation to handle missing data; results are reported in the Supplementary Materials (Tables S5-S8b).

In the following, we describe the steps of the analyses reported. First, we present weighted summary statistics of the demographic characteristics for the full sample and the subsample used in the analyses (see Table 1; for demographic characteristics divided by country for the full sample, a subsample only including single vs. married individuals, and a subsample including single vs. married/ co-habiting individuals, see Supplementary Materials, Tables S1, S2, and S3, respectively). Next, we conducted a linear regression to test the effects of marital status and gender on BMI, using marital status, gender, and their interaction as predictors; and age, indicators of socio-economic status, and country as covariates (Fig. 1). Then, we ran the same linear regression model for each country separately (not including country as covariate; Fig. $2 \mathrm{a}$ and b). In the next set of analyses we examined the relation between weight-related behaviors and BMI. First, using a linear regression model, we tested whether marital status and gender predicted weight-related behaviors differently (Fig. 3a and b; Table 2). To understand whether there were differences in eating- and exercise-related cognitions and behavior by marital status, linear regressions with marital status and eating- or exercise-related variables as predictors and BMI as outcome, were run separately for men and women (Table 3). Importantly, all analyses reported in this manuscript included interactions with gender or were separated by gender because gender has been suggested to differentially impact health and health-related behaviors (e.g. Rapp and Schneider, 2013; Worsley, 1988).

\section{Results}

Participant characteristics. Participants reported their gender, age, marital status, weight, height, and household size as well as 
Table 1

Participant characteristics (weighted).

\begin{tabular}{|c|c|c|c|}
\hline & & Full sample $(N=10226) \%$ & Subsample used in analyses $(N=4555) \%$ \\
\hline \multirow[t]{3}{*}{ Gender } & Male & 47.6 & 52.1 \\
\hline & Female & 52.4 & 47.9 \\
\hline & $\%$ Missing values & 0.0 & 0.0 \\
\hline \multirow[t]{7}{*}{ Age } & $16-19$ & 7.6 & 0.8 \\
\hline & $20-29$ & 16.8 & 11.5 \\
\hline & $30-39$ & 16.8 & 23.5 \\
\hline & $40-49$ & 17.6 & 20.3 \\
\hline & $50-59$ & 15.2 & 14.5 \\
\hline & $60+$ & 26.0 & 29.4 \\
\hline & $\%$ Missing values & 0.0 & 0.0 \\
\hline \multirow[t]{3}{*}{ Marital status } & Never married & 23.2 & 14.9 \\
\hline & Married & 50.2 & 85.1 \\
\hline & $\%$ Missing values & 0.5 & 0.0 \\
\hline \multirow[t]{5}{*}{ BMI } & Underweight $(\mathrm{BMI}<18.5)$ & 3.2 & 1.8 \\
\hline & Normal weight (BMI 18.5-24.9) & 47.7 & 43.8 \\
\hline & Overweight (BMI 25.0-29.9) & 33.4 & 38.4 \\
\hline & Obese $(\mathrm{BMI}>30)$ & 13.9 & 10.9 \\
\hline & $\%$ Missing values & 1.7 & 1.4 \\
\hline \multirow[t]{7}{*}{ Employment status } & Blue-collar worker & 22.4 & 16.1 \\
\hline & White-collar employee & 25.7 & 27.0 \\
\hline & Manager & 6.7 & 4.4 \\
\hline & Self-employed & 9.2 & 9.6 \\
\hline & Currently not working/retired & 28.5 & 38.1 \\
\hline & Never worked/other & 4.6 & 5.9 \\
\hline & \% Missing values & 2.9 & 0.6 \\
\hline \multirow[t]{4}{*}{ Income level } & Low & 31.0 & 29.6 \\
\hline & Medium & 31.5 & 35.9 \\
\hline & High & 15.1 & 14.5 \\
\hline & $\%$ Missing values & 22.4 & 20.0 \\
\hline \multirow[t]{4}{*}{ Education level } & Low & 29.2 & 28.1 \\
\hline & Medium & 45.3 & 44.4 \\
\hline & High & 24.8 & 27.1 \\
\hline & $\%$ Missing values & 0.7 & 0.4 \\
\hline \multirow[t]{5}{*}{ Household size } & 1 person & 16.0 & 14.9 \\
\hline & 2 persons & 30.2 & 43.3 \\
\hline & 3 persons & 23.1 & 18.3 \\
\hline & 4 and more persons & 30.7 & 23.5 \\
\hline & $\%$ Missing values & 0.0 & 0.0 \\
\hline \multirow[t]{10}{*}{ Country } & Austria & 1.6 & 1.9 \\
\hline & France & 11.8 & 11.8 \\
\hline & Germany & 16.2 & 19.0 \\
\hline & Italy & 11.9 & 11.1 \\
\hline & Netherlands & 3.1 & 4.6 \\
\hline & Poland & 7.4 & 5.5 \\
\hline & Russia & 27.0 & 26.4 \\
\hline & Spain & 9.2 & 7.9 \\
\hline & UK & 11.8 & 11.8 \\
\hline & $\%$ Missing values & 0.0 & 0.0 \\
\hline
\end{tabular}

Note. Employment status, income level, and education level refer to the head of household.

employment status, income level, and education level of the head of household (Table 1). BMI was calculated by dividing selfreported weight in kilograms by height in meters squared; socioeconomic status was operationalized as income, education level, and profession of the head of household. These variables were included as covariates in all analyses. Although height and weight were not measured directly, the self-reporting of both variables is more accurate in a personal interview situation than in settings in which the interviewee is not visible (e.g., telephone interviews; Ezzatti et al, 2006).

\subsection{Differences in $B M I$}

On average, married individuals had a higher BMI than never marrieds, consistent with the marriage-market explanation and different from the marriage-selection explanation (Fig. 1). A linear regression with BMI as dependent variable, marital status, gender, and their interaction as predictors, as well as age, indicators of socioeconomic status, and country as covariates, showed five main effects: marital status, $B=0.64, S E=0.32, p=.048$, gender, $B=-0.75, S E=0.18, p<.001$, age $B=0.06, S E=0.01, p<.001$, education of head of household $B=-0.68, S E=0.12, p<.001$, and country $B=0.12, S E=0.03, p<.001$. $R^{2}$ for the model was 0.070 . There was no interaction between marital status and gender, $B=0.20, S E=0.50, p=.684$. Importantly, results are comparable when including individuals that are co-habiting in the "married" category (see Table S5 in the Supplementary Materials).

Broken down by individual countries, the regularity of married individuals having a higher BMI than never marrieds emerged relatively consistently across countries (Fig. 2a and b). Specifically, married men in all nine countries had a higher BMI than never marrieds. Only in Italy was the difference in BMI large enough to be statistically significant $\left(B=1.51, S E=0.66, p=.021, R^{2}=0.103\right.$; results controlled for age and socioeconomic status). Married women in six of the nine countries had a higher BMI than women that had never been married, however, this difference was only significant in Russia $\left(B=1.75, S E=0.80, p=.029, R^{2}=0.176\right)$. The findings are similar when co-habitors are included in the group of 


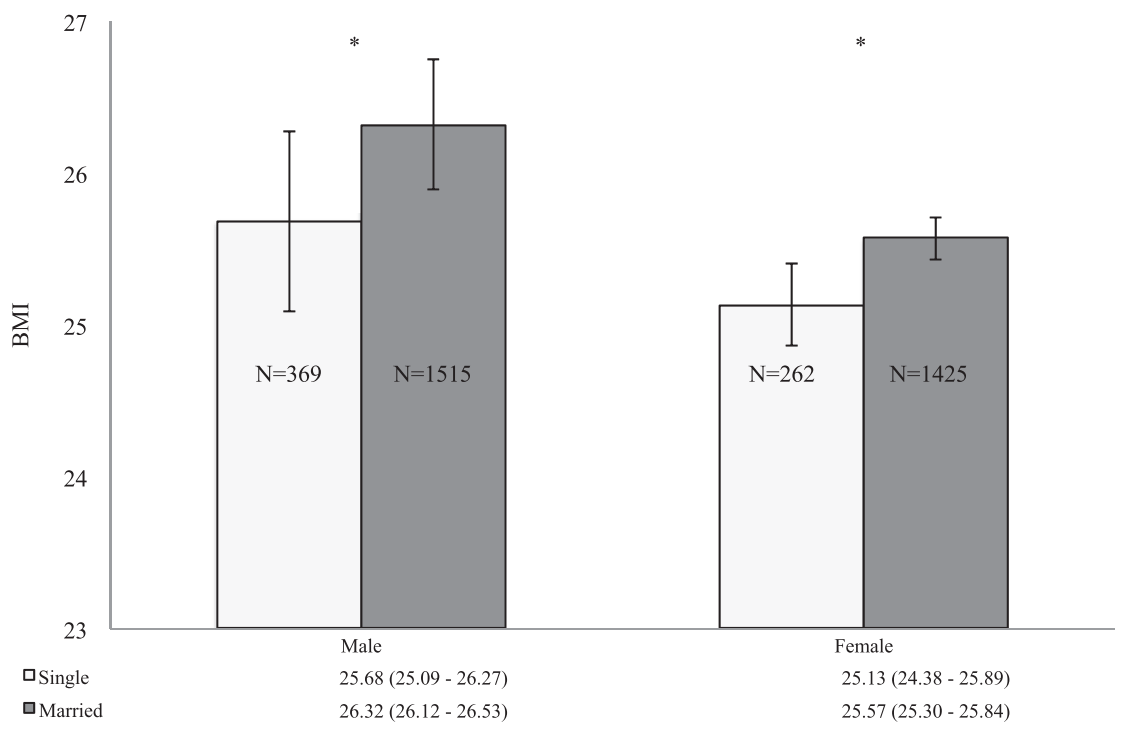

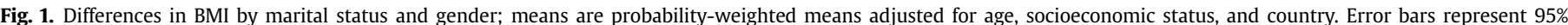
confidence intervals.

\section{(a) Men}

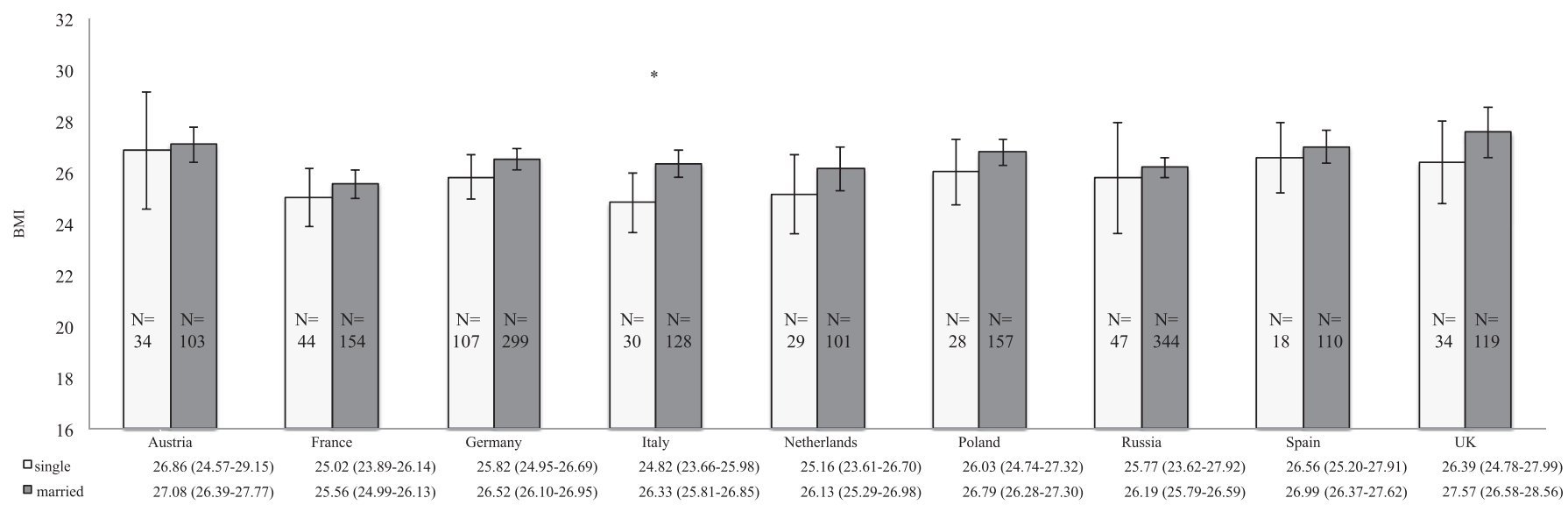

\section{(b) Women}

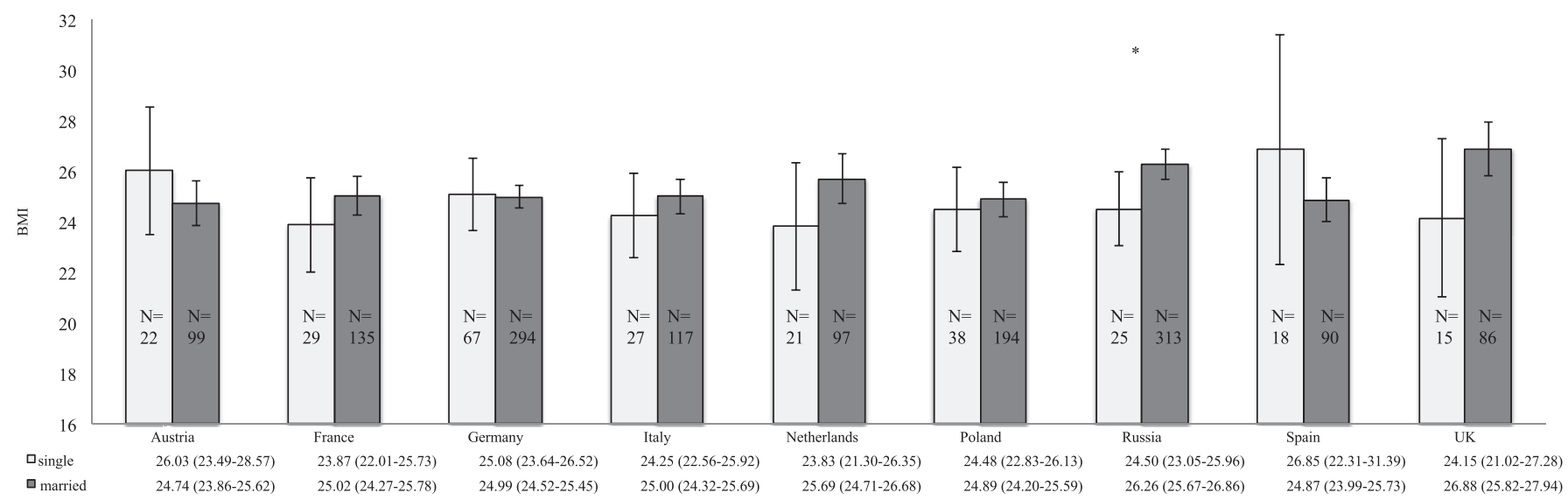

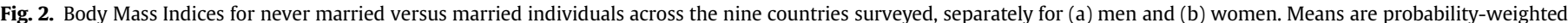
means adjusted for age and socioeconomic status. Error bars represent 95\% confidence intervals. 
(a) Men

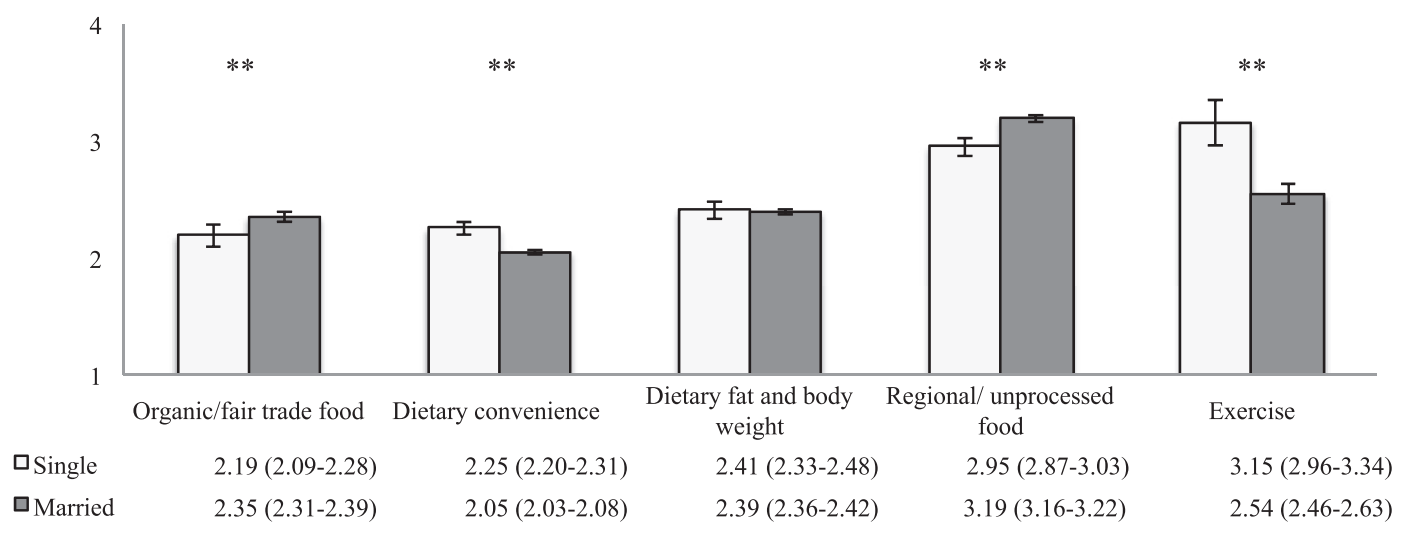

(b) Women

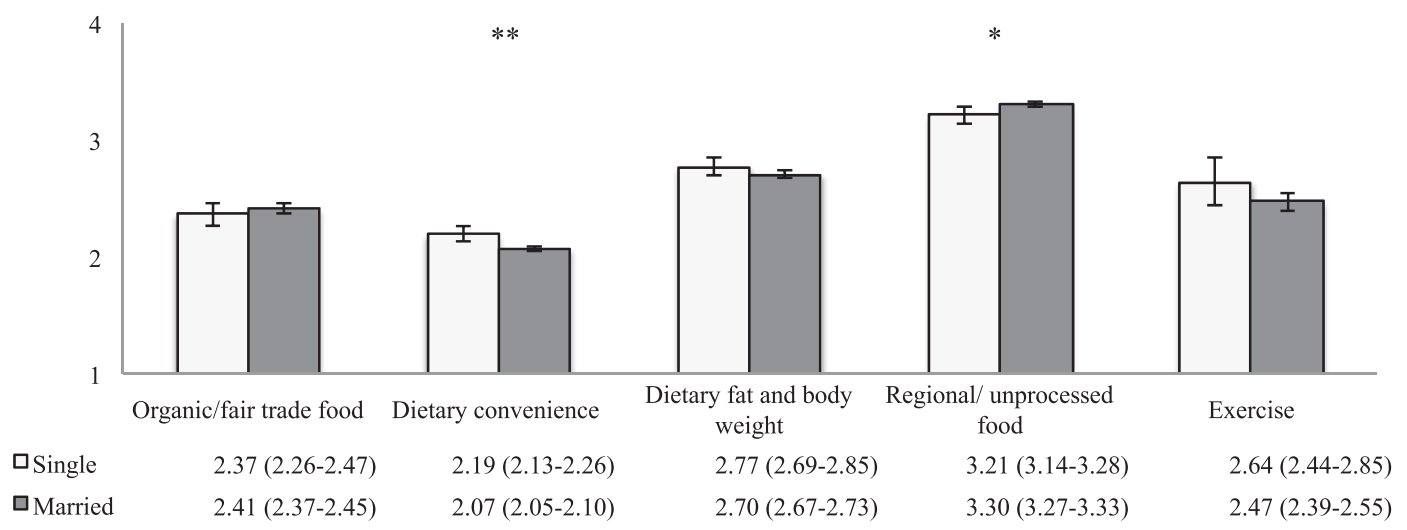

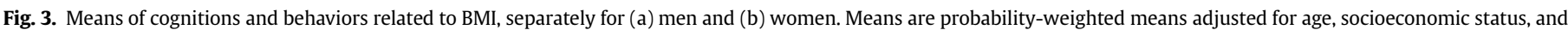
country. Error bars represent $95 \%$ confidence intervals. Behaviors related to BMI were rated on a scale from 1 (does not apply at all) to 4 (applies fully). ${ }^{* *} \mathrm{p}<.01,{ }^{*} \mathrm{p}<.05$.

Table 2

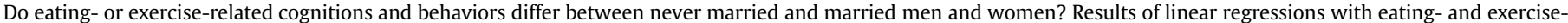

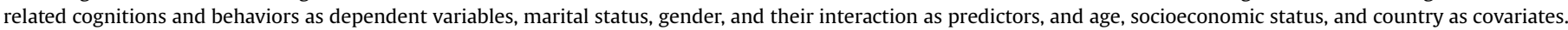

\begin{tabular}{|c|c|c|c|c|}
\hline & Marital status & Gender & Marital status* gender & $R^{2}$ \\
\hline Organic/fair trade food & $B=0.15, S E=0.05, p=.003$ & $B=0.07, S E=0.03, p=.013$ & $B=0.08, S E=0.07, p=.246$ & 0.012 \\
\hline Dietary convenience & $B=-0.20, S E=0.03, p<.001$ & $B=0.01, S E=0.02, p=.660$ & $B=-0.09, S E=0.04, p=.048$ & 0.086 \\
\hline Dietary fat and body weight & $B=-0.003, S E=0.04, p=.932$ & $B=0.31, S E=0.02, p<.001$ & $B=0.05, S E=0.06, p=.381$ & 0.110 \\
\hline Regional/unprocessed food & $B=0.25, S E=0.04, p<.001$ & $B=0.13, S E=0.02, p<.001$ & $B=0.15, S E=0.06, p=.007$ & 0.080 \\
\hline Exercise & $B=-0.57, S E=0.10, p<.001$ & $B=-0.10, S E=0.06, p=.092$ & $B=-0.37, S E=0.14, p=.009$ & 0.063 \\
\hline
\end{tabular}

married individuals (Table S6), or when missing data were handled with multiple imputations (Table S6).

\subsection{Weight-related behaviors and BMI}

Next, the marriage-protection explanation was tested against the negative-protection explanation. The former suggests that partners in a marriage have healthier lifestyles; the latter, that the unhealthy habits of one spouse migrate to the other. Five linear regressions-four for the eating-related factors and one for exercise behavior-were conducted. Eating- and exercise-related cognitions and behaviors were used as dependent variables, marital status, gender, and their interaction as predictors, and age, indicators of socioeconomic status, and country as covariates.

Relative to never marrieds, married people reported stronger preferences for regional/unprocessed food and paying less attention to dietary convenience across all countries; married men also paid more attention to organic/fair trade food than single men (Table 2, Fig. 3a and b). These results suggest that the dietary repertoire of partners in a marriage is of higher quality and involves healthier food, consistent with the marriage-protection explanation. Yet, this is only part of the story. In line with the negativeprotection explanation, at least married men also exercised significantly less (Fig. 3a and b).

Were there gender differences in behavior? Men and women differed in three eating-related cognitions (all but dietary convenience), with men generally reporting weaker preferences for organic/fair trade foods as well as regional/unprocessed foods, and paying less attention to dietary fat and body weight. There was an interaction effect between marital status and gender for the 
Table 3

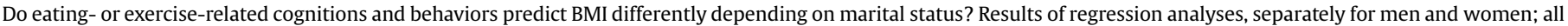
results controlled for age, socioeconomic status, and country.

\begin{tabular}{|c|c|c|c|c|}
\hline Predictors & Men & $R^{2}$ & Women & $R^{2}$ \\
\hline Organic/fair trade food & & 0.04 & & 0.11 \\
\hline Marital status & $B=0.22, S E=0.70, p=.755$ & & $B=0.99, S E=1.29, p=.440$ & \\
\hline Organic/fair trade food & $B=-0.53, S E=0.27, p=.047$ & & $B=-0.29, S E=0.55, p=.598$ & \\
\hline Marital status* organic/fair trade food & $B=0.27, S E=0.30, p=.377$ & & $B=-0.18, S E=0.57, p=.751$ & \\
\hline Dietary convenience & & 0.04 & & 0.11 \\
\hline Marital status & $B=-0.12, S E=1.50, p=.936$ & & $B=4.01, S E=2.59, p=.122$ & \\
\hline Convenience & $B=-0.29, S E=0.59, p=.620$ & & $B=1.89, S E=1.23, p=.126$ & \\
\hline Marital status* convenience & $B=0.38, S E=0.64, p=.543$ & & $B=-1.57, S E=1.26, p=.214$ & \\
\hline Dietary fat and body weight & & 0.05 & & 0.11 \\
\hline Marital status & $B=3.58, S E=0.91, p<.001$ & & $B=0.69, S E=1.99, p=.728$ & \\
\hline Attention to fat and body weight & $B=0.94, S E=0.32, p=.003$ & & $B=-0.49, S E=0.66, p=.455$ & \\
\hline Marital status* Attention to fat and body weight & $B=-1.19, S E=0.37, p=.001$ & & $B=-0.06, S E=0.70, p=.926$ & \\
\hline Regional/unprocessed food & & 0.04 & & 0.10 \\
\hline Marital status & $B=3.45, S E=1.36, p=.011$ & & $B=-1.75, S E=2.38, p=.461$ & \\
\hline Regional/unprocessed food & $B=0.56, S E=0.46, p=.226$ & & $B=-0.71, S E=0.71, p=.317$ & \\
\hline Marital status* Regional/unprocessed food & $B=-0.90, S E=0.50, p=.071$ & & $B=0.72, S E=0.75, p=.341$ & \\
\hline Exercise & & 0.05 & & 0.11 \\
\hline Marital status & $B=1.02, S E=0.82, p=.214$ & & $B=0.70, S E=0.79, p=.376$ & \\
\hline Exercise & $B=-0.09, S E=0.20, p=.661$ & & $B=-0.21, S E=0.21, p=.328$ & \\
\hline Marital status* Exercise & $B=-0.13, S E=0.21, p=.523$ & & $B=-0.08, S E=0.23, p=.744$ & \\
\hline
\end{tabular}

preferences for convenience food and regional/unprocessed food: never married men valued dietary convenience more, and purchased less regional/unprocessed food, than did married men or never married or married women. There was also an interaction between marital status and gender for exercise, with never married men exercising more than never married women or married men or women. Importantly, results replicated when co-habitors were included in the analyses or when missing data were handled with multiple imputations (see Table S7).

Next, to understand whether there were gender differences in cognitions and behavior dependent on marital status, linear regressions with marital status, eating- or exercise-related variables, and their interaction as predictors, and BMI as outcome, were run (Table 3). All regressions were controlled for effects of age, indicators of socioeconomic status, and country. For men, an interaction occurred. Specifically, the more attention never married men paid to dietary fat and body weight, the higher their BMI; for married men, in contrast, no such relation emerged. For women, there were no significant interactions between marital status and eating- or exercise-related cognitions and behaviors. Again, results were comparable when co-habitors were included in the analyses or when missing data were handled with multiple imputations (see Tables S8a und S8b).

\section{Discussion}

Information about BMI, marital status, and eating- and exerciserelated cognitions and behaviors obtained from representative samples in nine European countries was used to test for differences in the BMI of never married and married individuals. Collapsed across the nine countries, the data showed that, on average, never married participants had a lower BMI than married participants, consistent with the marriage-market explanation. Although this pattern generally emerged across most of the nine countries, the difference between never married and married individuals was relatively small and reached significance in only two countries. In view of the mixed findings previously reported, however, one pattern emerging across nine countries in this study is remarkably consistent: In any of the countries examined, married individuals never had a significantly lower BMI than never married individuals.

What explains this difference in BMI? Few previous studies have examined potentially weight-related cognitions or health behaviors as explanations for the link between BMI and marital status (e.g., Yannakoulia et al., 2008). To help fill this gap, we investigated the frequency of different eating- and exercise-related cognitions and behaviors. Married individuals reported stronger preferences for regional/unprocessed food and paid less attention to dietary convenience than never married individuals. Married men also paid more attention to organic/fair trade food than single men. All these cognitions and behaviors are consistent with the notion that married individuals are more likely to engage in healthprotective behaviors than never married individuals, consistent with the marriage-protection explanation. Yet, at the same time, at least married men exercised less often than never marrieds, consistent with the notion that key weight-controlling behavior is crowded out in marriage-a dynamic consistent with the negativeprotection explanation.

To conclude, these findings indicate that marriage is associated with both more health-promoting activities (more healthy food and less convenience food) and fewer health-promoting activities (less exercise, at least in men). Despite these behavioral differences, only one behavior proved to be differentially related to BMI in married versus never married men: awareness of dietary fat and body weight.

\subsection{Implications}

Our findings highlight the importance of social context for health and body weight. Previous studies have shown that spouses' body weight is correlated, particularly for obese spouses, and that obese parents are more likely to have obese offspring (Katzmarzyk et al., 2002). Thus, understanding how social institutions such as marriage contribute to health and dietary habits that are conducive to obesity is an important step towards understanding obesity in general. Further, our findings suggest that interventions targeted to weight control ought to be tailored to the social context of individuals. Insights into which health behaviors are generally reinforced in individuals who are married (e.g., healthier nutrition) and which are crowded out in marriage (e.g., reduced exercise) can facilitate the specific targeting of these behaviors in populations at risk for obesity. Our data suggest that this might be particularly the case in men.

Marriage is an important social institution. The vast majority of individuals get married at least once in their life. Although a 
number of studies have investigated the health consequences of marriage (e.g., Hahn, 1993; Musick and Bumpass, 2012; Sobal et al., 1992; Wilson and Oswald, 2005; Worsley, 1988), numerous questions deserve further attention, including national influences, potential mechanisms underlying the link between marriage and BMI, and gender differences. This study was a first attempt to address those questions by examining the consistency of the link between marital status and BMI across different countries, potential underlying cognitions and behaviors, as well as gender differences. Two lessons can be learned from our results. First, notwithstanding the relatively consistent picture that emerged across all nine countries, the positive link between marital status and BMI did not arise in all countries, and often did not achieve significance. Obviously, the effects are small and this may be the key to the previously mixed findings. Second, there is more than one behavior behind the link between marital status and BMI. Marriage brings along many changes (of which only a few could be examined in this study), some of which are conducive to a healthy diet and some of which impede the goal of maintaining body weight.

\subsection{Strengths and limitations}

The strength of the current investigation is the database: The same questions were posed to nine representative samples, thus permitting a comparison of nine European countries that, taken together, represent a substantial proportion of the European population. For a number of these countries, findings concerning the relation between marital status and BMI have, to our knowledge, not previously been reported. Responses were collected using faceto-face interviews, ensuring high quality of the data.

However, there are also a number of limitations. One, the data are cross-sectional. Therefore, causal inferences cannot be drawn and changes over time could not be tested. For example, it is not possible to disentangle whether never married men with a higher BMI paid attention to dietary fat and body weight because they felt they had weight problems or whether that very awareness caused an increase in BMI. Also, weight and height were self-reported, and such reports can lead to underestimation of BMI (Gorber et al., 2007; May et al., 2013). However, asking about height and weight in a personal interview situation, as was the case in our study, yields more accurate responses than, for example, in a telephone setting (Ezzati et al., 2006). It is important to note, that BMI is only an approximate predictor of health and health risk; other measures such as weight circumference would provide important additional information to assess the health consequences of a higher BMI in married individuals (Janssen et al., 2004). Further, the analyses reported focus on how marital status and eating- or exerciserelated behaviors were associated with BMI. Of course, many additional factors may be relevant to the development of body weight, including length or quality of relationship (e.g., Klein, 2011). Future research should address these additional factors by comparing BMI trajectories after changes in marital status across longitudinal representative international samples. Lastly, participants were selected using quota sampling; while this method yields data that are representative for the previously defined segments of the population, interviewers select participants due to the predefined criteria, which might lead to selection bias. To minimize selection bias in the current study, each interviewer interviewed a maximum of four study participants. Importantly, also randomsampling, which is theoretically free of selection bias because all individuals of a population have the same probability to be included, is subject to biases in practice. For example, participants in studies using random dial selection have been shown to be better educated than a sample representative for the population at large, because well-educated individuals are more likely to participate
(Wang et al., 2009).

\subsection{Conclusions}

Are married people really healthier? The short answer, yes, is too simplistic. Although the results show generally higher engagement in health-promoting eating cognitions and behaviors among married individuals, particularly men, married individuals had a higher BMI and also exercised less-both risk factors for poorer health. Importantly, there were surprisingly few country differences in the relation between marital status and BMI across the nine European countries considered, despite considerable differences in factors such as divorce rates. Our results suggest that-despite generally more favorable eating behavior-marriage is linked to higher BMI.

\section{Conflict of interest}

This study did not receive financial support from any third party. None of the authors has a conflict of interest.

\section{Appendix A. Supplementary data}

Supplementary data related to this article can be found at http:// dx.doi.org/10.1016/j.socscimed.2015.06.001.

\section{References}

Averett, S.L., Argys, L.M., Sorkin, J., 2013. In sickness and in health: an examination of relationship status and health using data from the Canadian National Public Health Survey. Rev. Econ. Househ. 11, 599-633.

Averett, S., Korenman, S., 1996. The economic reality of the beauty myth. J. Hum. Resour. 31, 304-330.

Averett, S.L., Sikora, A., Argys, L.M., 2008. For better or worse: relationship status and body mass index. Econ. Hum. Biol. 6, 330-349.

Ball, K., Mishra, G., Crawford, D., 2002. Which aspects of socioeconomic status are related to obesity among men and women? Int. J. Obes. 26, 559-565.

Brown, S.L., 2000. The effect of union type of psychological well-being: depression among cohabitors versus marrieds. J. Health Soc. Behav. 41, 241-255.

Dinour, L., Leung, M.M., Tripicchio, G., Khan, S., Yeh, M.C., 2012. The association between marital transitions, body mass index, and weight: a review of the literature. Hindawi Publishing Corporation J. Obes. 2012 http://dx.doi.org/ 10.1155/2012/294974. Article ID 294974, 16 pages.

Eurostat, 2015. Marriage and Divorce Statistics. Available from: http://ec.europa.eu eurostat/statistics-explained/index.php/Marriage and divorce statistics.

Ezzati, M., Martin, H., Skjold, S., Hoorn, S.V., Murray, C.J.L., 2006. Trends in national and state-level obesity in the USA after correction for self-report bias: analysis of health surveys. J. R. Soc. Med. 99, 250-257.

Fu, H.S., Goldman, N., 1996. Incorporating health into models of marriage choice: demographic and sociological perspectives. J. Marriage Fam. 58, 740-758.

Gorber, S.C., Tremblay, M., Moher, D., Gorber, B., 2007. Diagnostic in obesity comorbidities - a comparison of direct vs. self-report measures for assessing height, weight and body mass index: a systematic review. Obes. Rev. 8, 307-326.

Hahn, B.A., 1993. Marital status and women's health: the effect of economic marital acquisitions. J. Marriage Fam. 55, 495-504.

Heineck, G., 2006. Height and weight in Germany, evidence from the German socioeconomic panel, 2002. Econ. Hum. Biol. 4, 359-382.

Herman, C.P., Roth, D.A., Polivy, J., 2003. Effects of the presence of others on food intake: a normative interpretation. Psychol. Bull. 129, 873-886.

Horwitz, A.V., White, H.R., 1998. The relationship of cohabitation and mental health: a study of a young adult cohort. J. Marriage Fam. 60, 505-514.

Janssen, I., Katzmarzyk, P.T., Ross, R., 2004. Waist circumference and not body mass index explains obesity-related health risk. Am. J. Clin. Nutr. 79, 379-384.

Katzmarzyk, P.T., Hebebrand, J., Bouchard, C., 2002. Spousal resemblance in the Canadian population: implications for the obesity epidemic. Int. J. Obes. 26, $241-246$.

Khan, C.M., Stephens, M.A.P., Franks, M.M., Rook, K.S., Salem, J.K., 2013. Influences of spousal support and control on diabetes management through physical activity. Health Psychol. 32, 739-747.

Kittel, F., Rustin, R.M., Dramaix, M., Debacker, G., Kornitzer, M., 1978. Psycho-sociobiological correlates of moderate overweight in an industrial population. J. Psychosomatic Res. 22, 145-158.

Klein, T., 2011. "Durch dick und dünn." Zum Einfluss von Partnerschaft und Partnermarkt auf das Körpergewicht (The influence of relationship status and marriage market on body weight). Kölner Z. für Soziol. 63, 459-479. 
Kohn, J.L., Averett, S.L., 2014a. Can't we just live together: new evidence of the effect of relationship status on health. J. Fam. Econ. Issues. 35, 295-312.

Kohn, J.L., Averett, S.L., 2014b. The effect of relationship status on health with dynamic health and persistent relationships. J. Health Econ. 36, 69-83.

Kreider, R.M., Ellis, R., 2011. Number, Timing, and Duration of Marriages and Divorces: 2009 (Current Population Reports P70-125). Retrieved from U.S. Census Bureau website. http://www.census.gov/prod/2011pubs/p70-125.pdf.

Lundborg, P., Nystedt, P., Lindgren, B., 2007. Getting ready for the marriage market? the association between divorce risks and investments in attractive body mass among married Europeans. J. Biosoc. Sci. 39, 531-544.

May, A.M., Barnes, D.R., Forouhi, N.G., Luben, R., Khaw, K.T., Wareham, N.J. Peeters, P.H.M., Sharp, S.J., 2013. Prediction of measured weight from selfreported weight was not improved after stratification by body mass index. Obesity 21, E137-E142.

Meltzer, A.L., Novak, S.A., McNulty, J.K., Butler, E.A., Karney, B.R., 2013. Marital satisfaction predicts weight gain in early marriage. Health Psychol. 32, 824-827.

Mukhopadhyay, S., 2008. Do women value marriage more? the effect of obesity on cohabitation and marriage in the USA. Rev. Econ. Househ. 6, 111-126.

Musick, K., Bumpass, L., 2012. Re-examining the case for marriage: union formation and changes in well-being. J. Marriage Fam. 74, 1-18.

Noppa, H., Bengtsson, C., 1980. Obesity in relation to socioeconomic-status: a population study of women in Goteborg, Sweden. J. Epidemiol. Community Health 34, 139-142.

Rapp, I., Schneider, B., 2013. The impacts of marriage, cohabitation and dating relationships no weekly self-reported physical activity in Germany: a 19-year longitudinal study. Soc. Sci. Med. 98, 197-203.

Sarlio-Lähteenkorva, S., Lissau, I., Lahelma, E., 2005. The social patterning of relative body weight and obesity in Denmark and Finland. Eur. J. Public Health 16 $36-40$.

Sobal, J., Rauschenbach, B.S., 2003. Gender, marital status, and body weight in older U.S. adults. Gend. Issues 21, 75-94.
Sobal, J., Rauschenbach, B.S., Frongillo Jr., E.A., 1992. Marital status, fatness and obesity. Soc. Sci. Med. 35, 915-923.

Sund, E.R., Jones, A., Midthjell, K., 2010. Individual, family, and area predictors of BMI and BMI change in an adult Norwegian population: findings from the HUNT study. Soc. Sci. Med. 70, 1194-1202.

Tovée, M.J., Reinhardt, S., Emery, J.L., Cornelissen, P.L., 1998. Optimum body-mass index and maximum sexual attractiveness. Lancet 352, 548.

United Nations Statistics Division, 2014. Demographic Yearbook. Available from: http://unstats.un.org/unsd/demographic/products/dyb/dyb2011.htm.

Umberson, D., Karas Montez, J., 2010. Social relationships and health: a flashpoint for health policy. J. Health Soc. Behav. 51, 54-66.

Umberson, D., Liu, H., Powers, D., 2009. Marital status, marital transitions, and body weight. J. Health Soc. Behav. 50, 327-343.

Waite, L., Gallagher, M., 2000. The Case for Marriage: Why Married People Are Happier, Healthier and Better off Financially. Doubleday, New York.

Wang, P.P., Dicks, E., Gong, X., Buehler, S., Zhao, J., Squires, J., Younghusband, B., McLaughlin, J.R., Parfrey, P.S., 2009. Validity of random-digit-dialing in recruiting controls in a case-control study. Am. J. Health Behav. 33, 513-520.

Wilson, S.E., 2012. Marriage, gender and obesity in later life. Econ. Hum. Biol. 10, 431-453.

Wilson, C.M., Oswald, A.J., 2005. How Does Marriage Affect Physical and Psychological Health? a Survey of the Longitudinal Evidence. IZA Discussion Paper No. 1619.

World Health Organization (WHO), 2013. Obesity and Overweight. Fact sheet No. 311. Geneva, Switzerland: Author. Retrieved from. http://www.who.int/ mediacentre/factsheets/fs311/en/.

Worsley, A., 1988. Cohabitation-gender effects on food consumption. Int. J. Biosoc. Res. 10, 107-122.

Yannakoulia, M., Panagiotakos, D., Pitsavos, C., Skoumas, Y., Stafanadis, C., 2008. Eating patterns may mediate the association between marital status, body mass index, and blood cholesterol levels in apparently healthy men and women from the ATTICA study. Soc. Sci. Med. 66 (11), 2230-2239. 